\title{
Repeat dosing of rocuronium after reversal of neuromuscular block by sugammadex
}

\author{
Goh Matsuki, MD • Osamu Takahata, MD, PhD • \\ Hiroshi Iwasaki, MD, PhD
}

Received: 25 February 2011/ Accepted: 12 May 2011/Published online: 26 May 2011

(c) Canadian Anesthesiologists' Society 2011

\section{To the Editor,}

Sugammadex specifically antagonizes the steroidal neuromuscular blocking agent (NMBA), rocuronium, ${ }^{1}$ and it also has affinity for other steroidal NMBAs. A period of $24 \mathrm{hr}$ is currently recommended before re-administering rocuronium after sugammadex. ${ }^{\text {A }}$ If neuromuscular block (NMB) is needed before this time interval ends, a nonsteroidal NMBA should be given; however, nonsteroidal NMBAs are not available clinically in Japan. We present herein a 35-yr-old male patient (weight $73 \mathrm{~kg}$, height $173 \mathrm{~cm}$ ) in whom NMB was achieved using rocuronium 19 min after administering sugammadex. The authors have obtained agreement from the patient for submission of this case report to a medical journal.

The patient was scheduled for elective parotidectomy, and his preoperative blood chemistry was within normal limits. Anesthesia was induced with propofol, and endotracheal intubation was facilitated using rocuronium $40 \mathrm{mg}$. Maintenance of anesthesia was achieved with sevoflurane, remifentanil, and fentanyl. Repetitive train-of-four (TOF) stimulation was applied at the ulnar nerve using a TOF Watch (Organon Ltd, Dublin, Ireland) monitor. Rocuronium $10 \mathrm{mg}$ was added every 30-40 min, for a total dose of $100 \mathrm{mg}$ over $204 \mathrm{~min}$. At the end of surgery, $60 \mathrm{~min}$ after rocuronium, sugammadex $200 \mathrm{mg}\left(2.75 \mathrm{mg} \cdot \mathrm{kg}^{-1}\right)$ was administered, and the patient's trachea was extubated.

After that, bleeding from the drainage tube and progressive bulging of the surgical field were observed. The otolaryngologists requested immediate re-exploration for hemostasis. We prepared to monitor NMB at the adductor

G. Matsuki, MD - O. Takahata, MD, PhD (ه) .

H. Iwasaki, MD, PhD

Asahikawa Medical University, Asahikawa, Hokkaido, Japan

e-mail: osamu@asahikawa-med.ac.jp pollicis muscle using a TOF-Watch ${ }^{\circledR} \mathrm{SX}$ with preload (the Hand Adapter, Organon, Oss, the Netherlands), and we obtained digitized data. Anesthesia was induced with propofol, remifentanil, and sevoflurane inhalation, and neuromuscular blockade was monitored throughout the second surgery. Peripheral skin temperature, measured at the thenar eminence of the palm, was maintained at $32.5-34.5^{\circ} \mathrm{C}$, and body temperature was maintained at $36.2-37.2^{\circ} \mathrm{C}$.

Rocuronium $70 \mathrm{mg}$ was administered $19 \mathrm{~min}$ after sugammadex, but the first twitch to TOF stimulation (T1) did not disappear $195 \mathrm{sec}$ after this dose so an additional $30 \mathrm{mg}$ was added (Figure). The first twitch disappeared $105 \mathrm{sec}$ after the second dose, for an onset time of $300 \mathrm{sec}$. Anesthesia was maintained using sevoflurane, remifentanil, and fentanyl.

A single response following post-tetanic stimulation (post-tetanic count) was observed $50 \mathrm{~min}$ after rocuronium, and T1 appeared at $64 \mathrm{~min}$. At the end of the second surgery, sugammadex $150 \mathrm{mg}$ was again administered when the train-of-four ratio was $16 \%$. The train-of-four ratio reached $102 \%$ within $150 \mathrm{sec}$, and the patient's trachea was extubated (Figure).

Cammu et al. examined the onset and duration of re-administration of $1.2 \mathrm{mg} \cdot \mathrm{kg}^{-1}$ rocuronium after sugammadex $4.0 \mathrm{mg} \cdot \mathrm{kg}^{-1}$ under propofol anesthesia in healthy volunteers. $^{2}$ They found that sugammadex prolongs the onset time of rocuronium when the time interval from sugammadex administration was $<25 \mathrm{~min}$. Our patient was given rocuronium $1.0 \mathrm{mg} \cdot \mathrm{kg}^{-1}$, and $\mathrm{T} 1 \mathrm{had}$ not disappeared after $195 \mathrm{sec}$, indicating that this dose was insufficient under

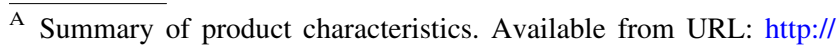
www.ema.europa.eu/docs/en_GB/document_library/EPAR___Product_ Information/human/000885/WC500052310.pdf (accessed May 2011).
} 


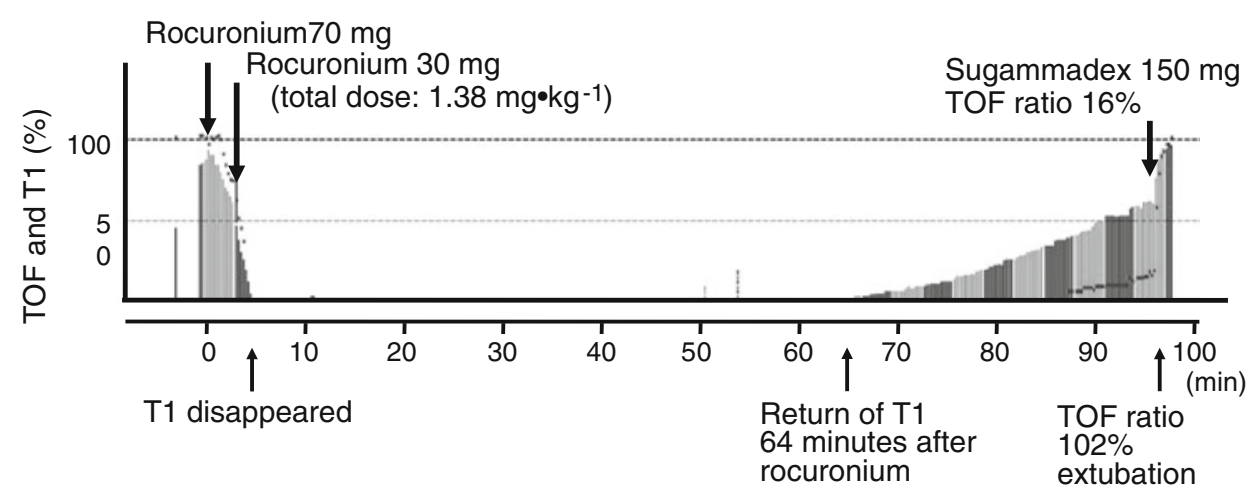

Figure Recording of the neuromuscular block induced by re-administration of rocuronium after sugammadex administration. Dotted lines represent the train-of-four (TOF) ratio expressed as a

sevoflurane anesthesia to achieve complete NMB $19 \mathrm{~min}$ after sugammadex.

The clinical duration (recovery of $\mathrm{T} 1$ to $25 \%$ ) of NMB action by rocuronium $1.2 \mathrm{mg} \cdot \mathrm{kg}^{-1}$ under isoflurane anesthesia has been reported to be $73 \mathrm{~min}^{3}$ Re-appearance of $\mathrm{T} 1$ in the present case was at $64 \mathrm{~min}$, and the duration of action was not noticeably shortened. This outcome is not consistent with Cammu et al.'s results, ${ }^{2}$ and the difference might be due to the anesthetics used. Sevoflurane has been reported to potentiate the effect of nondepolarizing NMBAs,${ }^{4}$ and in the present case, it may have prolonged the duration of action of re-administered rocuronium and potentiated it even a short time after sugammadex. Readministration of high-dose rocuronium after sugammadex would make the resultant duration of NMB unpredictable, especially when using sevoflurane, and monitoring NMB is mandatory in such a scenario. percentage. Bars represent the first twitch in response to TOF (T1) expressed as a percentage of the baseline value. Calibration could not be performed

Conflicts of interest None declared.

\section{References}

1. Epemolu $O$, Bom A, Hope F, Mason R. Reversal of neuromuscular blockade and simultaneous increase in plasma rocuronium concentration after the intravenous infusion of the novel reversal agent Org 25969. Anesthesiology 2003; 99: 632-7.

2. Cатmu G, de Kam PJ, De Graeve K, et al. Repeat dosing of rocuronium $1.2 \mathrm{mg} \mathrm{kg}^{-1}$ after reversal of neuromuscular block by sugammadex $4.0 \mathrm{mg} \mathrm{kg}^{-1}$ in anaesthetized healthy volunteers: a modelling-based pilot study. Br J Anaesth 2010; 105: 487-92.

3. Magorian T, Flannery KB, Miller RD. Comparison of rocuronium, succinylcholine, and vecuronium for rapid-sequence induction of anesthesia in adult patients. Anesthesiology 1993; 79: 913-8.

4. Naguib M, Lien CA. Pharmacology of muscle relaxants and their antagonists. In: Miller RD (Ed.). Miller's Anesthesia, 7th ed. Philadelphia: Churchill Livingstone Elsevier; 2010: 859-911. 